
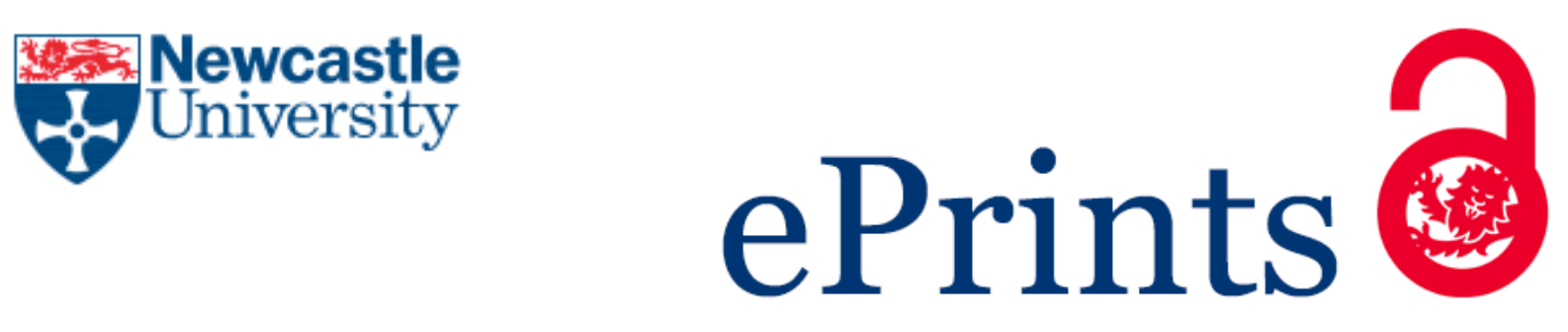

Scully JL.

A Mitochondrial Story: Mitochondrial Replacement, Identity and Narrative. Bioethics 2016, 31(1), 37-45

\title{
Copyright:
}

This is the peer reviewed version of the following article: Scully JL. A Mitochondrial Story: Mitochondrial Replacement, Identity and Narrative. Bioethics 2016, 31(1), 37-45, which has been published in final form at http://dx.doi.org/10.1111/bioe.12310. This article may be used for non-commercial purposes in accordance with Wiley Terms and Conditions for Self-Archiving.

DOI link to article:

http://dx.doi.org/10.1111/bioe.12310

Date deposited:

$04 / 01 / 2017$

Embargo release date:

14 December 2018 


\section{A MITOCHONDRIAL STORY: MITOCHONDRIAL REPLACEMENT, IDENTITY AND NARRATIVE}

\section{Keywords}

mitochondrial replacement, identity, narrative, mitochondrial donation

\begin{abstract}
Mitochondrial replacement techniques (MRTs) are intended to avoid the transmission of mitochondrial diseases from mother to child. MRTs represent a potentially powerful new biomedical technology with ethical, policy, economic and social implications. Among other ethical questions raised are concerns about the possible effects on the identity of children born from MRT, their families, and the providers or donors of mitochondria. It has been suggested that MRT can influence identity (i) directly, through altering the genetic makeup and physical characteristics of the child, or (ii) indirectly through changing the child's experience of disease, and by generating novel intrafamilial relationships that shape the sense of self. In this article I consider the plausibility and ethical implications of these proposed identity effects, but I focus instead on a third way in which identity may be affected, through the mediating influence of the wider social world on MRT's effects on identity. By taking a narrative approach, and examining the nature and availability of identity narratives, I conclude that while neither direct genetic nor indirect experiential effects can be excluded, social responses to MRT are more likely to have a significant and potentially damaging influence on the generation of MRT children's narratives of identity. This conclusion carries some implications for the collective moral responsibility we hold to ensure that MRT, if implemented, is practised in ethically justifiable ways.
\end{abstract}

\section{MITOCHONDRIAL REPLACEMENT TECHNOLOGIES}

The novel techniques of mitochondrial replacement currently being researched and developed, and the subject of this special issue, are intended as therapies for women affected by mitochondrial disease. Mitochondria are subcellular organelles with important functions in generating cellular energy. Conditions classed as mitochondrial diseases are most commonly due to an abnormality within the small amount of autonomous DNA carried by each mitochondrion (mtDNA), and present with a highly variable array of symptoms and prognoses. The most severe forms lead to death of a child prenatally, or to devastating physical or cognitive impairment and, often, early death.
Mitochondrial diseases are maternally transmitted 51 through the mitochondria in the cytoplasm of a woman's ovum. The aim of mitochondrial replacement technologies (MRTs) is to enable affected women to have children that are free of mitochondrial disease by transferring DNA from the nuclei of the intending parents' gametes into an enucleated egg provided by an unaffected donor ${ }^{1}$ replacing the mitochondria in an affected woman's egg. ${ }^{2}$ Although

${ }^{1}$ E. Haimes \& K. Taylor. Rendered invisible? The absent presence of egg providers in UK debates on the acceptability of research and therapy for mitochondrial disease. Monash Bioethics Review 2015; DOI $10.1007 /$ s40592-015-0046-7.

${ }^{2}$ There are a number of disputes about terminology within MRT, including the use of 'donation', 'replacement' or 'transfer', and whether the mitochondria or the nuclear genome should be seen as being mobile (see Haimes and Taylor, op. cit. note 1, for further discussion). In this

Address for correspondence: Jackie Leach Scully, Professor of Social Ethics and Bioethics, Policy, Ethics and Life Sciences Research Centre, Newcastle University, Claremont Bridge, Claremont Road, Newcastle upon Tyne NE1 7RU, UK.

Email: Jackie.scully@ncl.ac.uk 
numerous recent publications have discussed their clinical and epidemiological details, ${ }^{3}$ in comparison with conditions caused by mutations in the nuclear genome mitochondrial diseases and the peculiarities of their inheritance patterns are relatively unfamiliar both to bioethicists and the general public. ${ }^{4}$ Nevertheless, if as has been claimed roughly 1 in 400 people in the UK carry a disease-causing mitochondrial mutation, ${ }^{5}$ with around 9 in every 100000 clinically affected by mitochondrial disease, ${ }^{6}$ then mitochondrial conditions may present a significant health burden, and MRTs are set to become a new biomedical technology with major ethical, policy, economic and social implications.

The development of the two most promising techniques of mitochondrial replacement (maternal spindle transfer, MST, and pronuclear transfer, PNT) ${ }^{7}$ has been paralleled by growing international discussion of the ethics of their use. In the UK, the academic and policy examination of MRTs' ethical and public acceptability has involved several years of discussion, professional consultations carried out by the Nuffield Council on Bioethics $^{8}$ and the Human Fertilisation and Embryology Authority (HFEA), ${ }^{9}$ as well as public consultations run by the HFEA ${ }^{10}$ and the Department of Health. ${ }^{11}$ All of this led in 2015 to revision of the Human Fertilisation and Embryology Act 1990, as amended in 2008, so that

article, for simplicity I will use the conventional terminology of 'mitochondrial replacement' and 'mitochondrial donor' or 'provider'.

${ }^{3}$ S. DiMauro. A history of mitochondrial diseases. J Inherit Metab Dis 2011; 34: 261-76.

${ }^{4}$ P.F. Chinnery \& G. Hudson. Mitochondrial genetics. Br Med Bull. 2013; 106: 135-59.

${ }^{5}$ N. Manwaring, M.M. Jones, J.J. Wang et al. Population prevalence of the MELAS A3243G mutation. Mitochondrion 2007; 7: 230-3.

${ }^{6}$ A.M. Schaefer, R. McFarland, E.L. Blakely, L. He, R.G. Whittaker, R.W. Taylor, P.F. Chinnery and D.M. Turnbull. Prevalence of mitochondrial DNA disease in adults. Annal Neurology 2008; 63: 35-39.

${ }^{7}$ L. Craven, H.A. Tuppen, G.D. Greggains, S.J. Harbottle, J.L. Murphy, L.M. Cree, A.P. Murdoch, P.F. Chinnery, R.W. Taylor, R.N. Lightowlers, M. Herbert, and D.M. Turnbull. 2010. Pronuclear transfer in human embryos to prevent transmission of mitochondrial DNA disease. Nature 2010; 465: 82-85;M. Tachibana, M. Sparman, H. Sritanaudomchai, H. Ma, L. Clepper, J. Woodward, Y. Li, C. Ramsey, O. Kolotushkina, and S. Mitalipov. Mitochondrial gene replacement in primate offspring and embryonic stem cells. Nature 2009; 461: 367-372.

${ }^{8}$ Nuffield Council on Bioethics. Novel techniques for the prevention of mitochondrial DNA disorders: an ethical review. London: Nuffield Council on Bioethics; 2012.

${ }^{9}$ HFEA. 2011. Scientific review of the safety and efficacy of methods to avoid mitochondrial disease through assisted conception. London: Human Fertilisation and Embryology Authority; HFEA. 2013. Scientific review of the safety and efficacy of methods to avoid mitochondrial disease through assisted conception: Update. London: Human Fertilisation and Embryology Authority; 2013.

${ }^{10}$ HFEA. 2013. Mitochondria replacement consultation: Advice to government. London: Human Fertilisation and Embryology Authority.

${ }^{11}$ UK Department of Health. Mitochondrial donation: A consultation on draft regulations to permit the use of new treatment techniques to prevent the transmission of a serous mitochondrial disease from mother to child. 2014. London: HMSO; 2014
MRTs could be offered therapeutically to women affected by mitochondrial disease once (or if) they have been shown to be safe and effective.

Several of the ethical problems identified in both the professional and public bioethical discussion are very familiar from other biomedical contexts. ${ }^{12}$ High on the list are safety considerations (the ethics of using an innovative technology which by necessity lacks a track record of clinical safety; the cost/benefit balance of the intrusive follow-up of children born by MRTs that will be needed to evaluate longterm safety). Extensive discussion has also been given to whether mitochondrial replacement constitutes a germline modification, and if so whether the near-universal consensus against human germline genetic modification applies only to the nuclear and not to the mitochondrial genome. A further highly contentious question is whether the desire of affected people to have healthy children ${ }^{13}$ to which they are genetically related is a compelling enough reason to warrant the investment of time, funding and other resources that will be needed to make MRTs a clinical reality.

But MRTs also have some distinctive technical features that take us into less well trodden ethical territory. A person born through MRT will have nuclear DNA from the gametes of their father and mother, as in standard fertilization, but will also have additional 'third party' mtDNA from the mitochondrial donor. This is unlike other currently used methods of assisted reproduction, which involve only two sets of genetic material, and raises the question of whether third party mtDNA will in some way affect the identity or "essential characteristics ${ }^{14}$ of the person born after MRT. ${ }^{15}$ The potential effects on identity are hypothesised to come about through two essentially separate pathways. The first is directly, through the genetic component contributed by the donor mitochondrial DNA; the second is indirectly, through the novel family relationships set up by mitochondrial replacement.

In what follows I want to contribute to the debate on MRTs and identity. The central ethical questions are not just whether MRT effects a change in identity, but whether any such change will be great enough to be morally significant, and finally whether any significant

$\begin{array}{ll}12 \text { J.B. Appleby The ethical challenges of the clinical introduction of } & 104 \\ \text { mitochondrial replacement techniques. Med Health Care Philos 2015; } & 105 \\ \text { 18: 501-514; R. Dimond. Social and ethical issues in mitochondrial don- } & 106 \\ \text { ation. Br Med Bull 2015; 115: 173-182; F. Baylis. The ethics of creating } & 107 \\ \text { children with three genetic parents. Reproductive BioMedicine Online } & 108 \\ \text { 2013; 26: 531-534. } & 109 \\ 13 \text { That is, children unaffected by mitochondrial disease. People born } & 110 \\ \text { through MRT will remain as vulnerable to disease and disability in gen- } & 111 \\ \text { eral as anyone else. } & 112 \\ 14 \text { A.L. Bredenoord, W. Dondorp, G. Pennings, and G. De Wert. Ethics } & 113 \\ \text { of modifying the mitochondrial genome. J Med Ethics 2011; 37:97-100. } & 114 \\ 15 \text { A. Wrigley, S. Wilkinson S, Appleby JB. Mitochondrial replacement: } & 115 \\ \text { ethics and identity. Bioethics 2015; 29: 631-638. } & 116\end{array}$ 
change in identity would actually be undesirable. To address questions of identity change it helps to be as clear as possible about what identity is, and it is disappointing that much of the public and some of the academic debate has not done so. What we mean by identity is dependent on specific background theories of the self, and how selfhood is formed and maintained over a lifetime; whether and in what way MRT is considered to change identity depends on which background theory of identity is being deployed. In this discussion my main focus will be on a third route to changing identity, through effects on social identity, and in particular how that is influenced by narrative. First, however, I outline some current thinking about identity and its constitution, and the concerns that have been raised about the two pathways to altering identity I just mentioned. My argument is not that these other factors influencing identity are unimportant, but that bioethics' neglect of social effects on the emerging sense of self has hampered its examination of MRT's potential (and that of other reproductive technologies) to influence personal identity.

\section{GENETIC IDENTITY}

does is provide essential components for cellular energy production: this is clearly important to the organism's survival, but it isn't what we normally think of as an identity-forming characteristic. According to this argument, mtDNA is qualitatively irrelevant to the child's identity because of the kind of features it codes for. In addition, because the nuclear DNA contributed by the parents provides over $99.9 \%$ of the total genetic material, the contribution of the mitochondrial donor has been considered quantitatively irrelevant to identity-forming characteristics. The qualitative and quantitative insignificance of mtDNA has been prominent in both professional and public debates, and was used in the HFEA's arguments justifying the first licences for preclinical research on MRTs. Nevertheless, it can be challenged. Although the current consensus is that mtDNA has nothing to do with essential functions other than cellular energy metabolism, scientists also acknowledge that our understanding of mitochondria is far from complete and that consensus may change. ${ }^{17}$ In that case, the function of mtDNA might no longer be irrelevant, and the amount involved could become highly significant.

\section{THE ILLNESS EXPERIENCE}

The idea that identity is predominantly to do with traits directly determined by genes is roundly rejected by most commentators today as a discredited genetic essentialism, ${ }^{18}$ replaced by a more nuanced view in which personal identity is shaped by life experience as well as genetic input. From this perspective, modifying the mitochondrial genome affects the identity of the recipient not because of changes in the DNA sequences or in identityforming characteristics, but through the resulting transformation of that person's experience of health. ${ }^{19}$ Successful mitochondrial replacement will produce a child who does not suffer the well documented, devastating effects of mitochondrial disease, ${ }^{20}$ and 'a person without a mtDNA disease will have a different life experience, a different biography and perhaps also a different character' from one who does experience mtDNA disease. $^{21} \mathrm{He}$ or she may well be considered to be a 'different person'. The genetically produced change is intended to affect the mtDNA recipient's life for the

\footnotetext{
${ }^{17}$ D.R. Thorburn, H.H. Dahl, K.K. Singh. The pros and cons of mitochondrial manipulation in the human germ line. Mitochondrion 2001; 1 : 123-127.

${ }^{18}$ R. Dimond R. Social and ethical issues in mitochondrial donation. Br Med Bull 2015; 115: 173-182; 177.

19 A.L. Bredenoord et al., op.cit. note 14, p.5.

${ }^{20}$ P.N. Ossorio. Inheritable genetic modifications: do we owe them to our children. In Designing our descendants: the promise and perils of genetic modification. A.R. Chapman and M.S. Frankel, eds. Baltimore and London: Johns Hopkins University Press; 2003; 252-71.

${ }^{21}$ A.L. Bredenoord et al., op.cit, note 14, p.5: 99.
} 
better, by preventing disease; since it is not ethically troubling to intervene in other ways to prevent individuals going through disease experiences, then disease prevention by itself cannot be a reason to reject the use of MRT. $^{22}$

\section{FAMILIAL EFFECTS, OR 'THREE- PARENT BABIES'}

A different route to possible identity change is through alterations in the dynamics of relationships within families 10 using MRT. These have sometimes been described as psy1 chosocial effects; I will refer to them as familial effects on 12 identity to distinguish this more intimate family arena 3 from MRT's broader social context, which I will be dis4 cussing in more detail. ${ }^{23}$ Just like the experience of illness, these (putative) effects are the consequence of changing the genetic constitution, but not an unmediated one.

People who would be born through MRT are often described as 'three person' or 'three parent' children, or more accurately as having three genetic parents ${ }^{24}$ or three genomic contributors. ${ }^{25}$ The slippery terminology highlights the feature of MRT that many people find the most disturbing. Having three (social) parents is historically not unusual; being born as a result of reproductive input from three separate individuals through gamete or embryo donation, although statistically unusual is not unprecedented; but having contributions from three genomes is novel. ${ }^{26}$ The question is whether the novelty of this arrangement could have a significant effect on the child and future adult's sense of self.

Although the phrase 'three parents' has been criticized for suggesting that the sheer provision of mitochondrial material is equivalent to parenthood, it has nevertheless

\footnotetext{
${ }^{22}$ It follows from this is that if the avoidance of the disease experience is the most salient form of identity change, then in terms of the ethics of identity it doesn't matter whether this happens through a change in the mitochondrial DNA makeup of a person or through a change in the nuclear DNA makeup. Altering mitochondrial DNA prevents a person experiencing disease, and the effect on that person's identity is the same as if a modification of the nuclear genome had done the same thing. This conclusion makes the distinction between nuclear and mitochondrial DNA less clear, and that in turn has implications for the legitimacy of heritable nuclear DNA modification. I don't discuss this further here.

${ }^{23}$ Note also that some authors separate the ethics of MRT identity effects from the ethics of 'having 3 genetic parents'. However, since both the intrafamiliar relationship dynamic and the social framing of this genetic relationship and family structure are important in forming the child's sense of identity, both are also highly relevant to the debate on MRT identity effects.

${ }^{24}$ F. Baylis. The ethics of creating children with three genetic parents. Reproductive Bio Medicine Online 2013; 26: 531-534.

${ }^{25}$ E. Haimes and K. Taylor. Rendered invisible? The absent presence of egg providers in UK debates on the acceptability of research and therapy for mitochondrial disease. Monash Bioethics Review 2015 DOI $10.1007 /$ s40592-015-0046-7.

${ }^{26}$ Nuffield Council on Bioethics, op.cit. note 8, p.3.
}

proved extremely persistent in the popular media and parliamentary discussion. The debate over terminology reflects the ongoing uncertainty over exactly what kind of contribution the mitochondrial replacement makes. ${ }^{27}$ Will this unprecedented direct genetic link between three adults and a child disrupt the 'normal' parent-child relationship(s) and so cause damage to the psychological wellbeing, and by implication the emerging identity, of the child? Perhaps the child's emerging sense of self could in some way become confused through knowing that a third person was involved in their conception, unlike their peers; children might not be able to understand why the mitochondrial donor is not included in family events and communications; tensions may develop, if the child wants more information about the mitochondrial donor than parents are able or willing to provide. ${ }^{28}$ It's worth remembering that problems might also arise even if the child does not know how she came to be born, if the parents' or family's knowledge that MRT was used affects how they relate to her; for example, if an unwanted characteristic of their child is attributed to the influence of donor mtDNA. However, against these projected concerns can be set the range of experience gained since the 1970s from other forms of assisted reproduction that have produced family structures and relationships that were, initially, equally unfamiliar. Accumulated anecdotal and some empirical knowledge suggests that family structures are flexible, and familial networks resilient enough to accommodate a wide variety of parent-child relationships without causing psychological damage. Recent empirical studies of children born through gamete or embryo donation show no evidence of any distinctive psychological or emotional harm due to their unconventional family structures. ${ }^{29}$ Use of donor gametes, particularly donor insemination, has caused difficulties in some families, but these seem principally related to secrecy rather than the use of donor gametes per se. ${ }^{30}$ Of course, at the moment there

27 J. Cohen \& M. Alikani. The biological basis for defining bi-parental or tri-parental origin of offspring from cytompasmic and spindle transfer. Reprod Biomed Online 2013; 26: 535-537.

${ }^{28}$ The proposed HFEA regulations stipulate that licensed clinics will disclose only non-identifying information about the donor to a child born through MRT who seeks that information after the age of 16 .

${ }^{29}$ E. Basatemur \& A. Sutcliffe. Follow-up of children born after ART. Placenta 2008; 29; 135-140; E.C. Iloi \& S. Golombok. Psychological adjustment in adolescents conceived by assisted reproduction techniques: a systematic review. Human Reproduction Update 2015; 21: 84-96; C.S. Hahn. Review; psychosocial well-being of parents and their children born after assisted reproduction. J Pediatr Psychol 2001: 26; 525-538; K. Wagenaar, J. Huisman, P.T. Cohen-Kettenis \& H.A. Delemarre-van de Waal. An overview of studies on early development, cognition, and psychosocial well-being in children born after in vitro fertilization. J Dev Behav Pediatr 2008: 29; 219-230.

${ }^{30}$ E. Lycett, K. Daniels, R. Curson \& S. Golombok. Offspring created as a result of donor insemination; a study of family relationships, child adjustment, and disclosure. Fertil. Steril 2004: 82; 172-179; E. Lycett, K. Daniels, R. Curson, \& S. Golombok. School-aged children of donor 34 35 36 37 38 39 40 41 42 43 45 46 47 48 49 50 51 52 53 54 55 56 57 58 59 $\infty$ (1) . (3) 64 65 66 67 68 69 93 94 96 97 102 103 104 105 105
106 107 108 109 10 111 112 
1 are no MRT children and therefore no equivalent data on the psychological health of post-MRT children and their families. Moreover, the existing studies focus on psychological health and family functioning and not directly on identity formation. Still, these data provide some reassurance that the identities of children within MRT families will not be different from, or more dysfunctional than, those of 'normal' children.

\section{SOCIAL IDENTITY}

The discussion of MRT and identity has been dominated by the effects of gene action and family dynamics, both of which are relatively small-scale, narrowly focused processes. But what about the ways in which the development of selfhood is mediated through broader social factors extending beyond the individual and family? In this section I will give a (necessarily brief) sketch of what it means to have an identity formed within and by the social world, and take one approach to analysing socially mediated identity - through the action of narrative - to consider how MRT might influence a person's sense of self.

Social theorists and an increasing number of philosophers of the self argue that it is impossible to conceive of any aspect of a human individual developing or existing in isolation from society. ${ }^{31}$ As much as materially and genetically influenced features (such as the physical characteristics that indicate their sex), a person's identity is formed by the cultural forces that define which features of a person are important for knowing who and what they are (e.g. that sex and gender are worth noticing), and what these features signify in a particular social context and relational network (e.g. whether or not a woman is dressed appropriately according to prevailing norms). Identity features are markers for a variety of ontological and social categories, and among the most basic of these are to do with family relationships. My understanding of myself as a person with a mother and a father, or a mother and a stepfather, or two mothers, or (potentially through MRT) three genetic contributors, is acquired from everyday experiences (the things that happen between me and these family members), and also from the accounts my family and the communities around provide about who these people are and what my relationship to them is. Whether Moira sleeps at my house, if others refer to her as my mother, whether she is invited to school parents' evening or has her name on my birth certificate, all contribute to my understanding of myself as her daughter. So any examination of MRT's identity effects also needs to address the questions of whether

insemination; a study of parents' disclosure patterns. Hum. Reprod 2005: $20 ; 810-819$.

${ }^{31}$ S. Lawler. Identity. Cambridge: Polity Press; 2008; 5. socially mediated identity will be affected at all by the use of the technology, and if so whether any resulting change in identity could be harmful to the child, its family or even society in general.

\section{NARRATIVE IDENTITY}

Social models of identity deploy a range of theoretical frameworks and emphases. Some highlight the management of a person's multiple identities across their various social roles, or the formation of one identity through opposition to others. Some emphasise socio-political structures that shape the development of selves, others the ceaseless microinteractions between individuals in daily life. Feminist approaches are notably sensitive to the power dynamics of social categories and the constraining or liberating effects of gendered relations on identity. Nevertheless, tracing how social structuring 'gets into' the individual sense of self is not easy, requiring as it does some analytic traction on multiple macro, meso and micro influences coming together. Since the later twentieth and early twenty-first century, the 'narrative turn' in several disciplines ${ }^{32}$ has provided a powerful lens through which to conceptualise identity as derived from the stories told by ourselves to ourselves, ourselves to others and others to us. ${ }^{33}$

A personal sense of self accumulates out of the ascription and recognition, by ourselves and others, of narrative fragments drawn from a slowly evolving cultural repertoire of identity-forming stories. Stories tell us how families are made and behave, what a good parent does, the paths a son's relationship with his mother might take, and so on. The narrative construction of identity is therefore deeply socially embedded, and moreover the options that people have are limited by the materials available at that time and in that place. An important point that theories of narrative tend to underemphasize is that identity narratives aren't coherent literary constructions: they are necessarily fragmentary and incomplete accretions over time out of available tales that more-or-less work. If my partner dies, for example, my new identity might draw on the broad elements of the narrative of widowhood that have long been understood throughout my community, but the story options open to me (staying single; remarriage; partnership without marriage, etc) and the precise way in which I negotiate them as an early twenty-first century, mixed-race woman, which bits I find resonant and which I leave behind, are what make my version distinctive. Ultimately, when I make an identity claim through a story I tell about

\footnotetext{
${ }^{32}$ R.J. Berger \& R. Quinney, eds. Storytelling sociology: Narrative as 101 social inquiry. Boulder, CO: Lynne Riener Publishers; 2005.

${ }_{33}$ M. Somers. The narrative constitution of identity: a relational and 103 network approach. Theory and Society 1994; 23: 605-649. . 56 57 58 59 60 61 62 63 64 65 66 67 68 69 70 71 72 75 76 77 78 79 80 81 82 . . 85 86 87 88 89 90 91 92 93 94 95 96 (n) 
myself, the plot or characters need to be familiar enough that others recognize my claim as plausible; the identity ascribed to me through others' accounts, similarly, must appear to me to be a reasonably accurate description of who I feel myself to be. From this perspective, identity is not to be found in the genome alone, nor in lived experience as such, but 'in the world in which we live and the stories we construct and are able to maintain'. ${ }^{34}$

The narrative turn has proved both conceptually and methodologically rich. It is not that a narrative approach is the only or best way of conceptualizing how identities form within the social world, but that it provides a useful and relatively straightforward analytic framework with which to explore how political structures and social institutions, cultural resources and personal biography all interweave to generate a meaningful subjectivity. A narrative approach also has the advantage of conveying a feel of the dynamism of identity and its potential for change over time, as well as the limits to such change.

The ethical significance of identity narratives lies in their effect on some morally relevant aspects of a person's life. Theorists interested in the ethics of identity have particularly focused on the connection between identity and the capacities for agency, autonomy and authenticity. Philosophers like Hilde Lindemann, ${ }^{35}$ Marya Schechtman ${ }^{36}$ and Paul Benson ${ }^{37}$ have different takes on this, but share the essential view that the sense someone has of themselves as subjects of their lives is fundamental to self-determination; 'agency' is the word we use for the activity of our identities in the social world. That is, in order to be agents 'present or engaged in their actions as free agents are, [people] must have a sense of who they are, and that sense of selfhood must be capable of being disclosed in their conduct ${ }^{38}$ we need to have a view of ourselves as the kind of person who is competent to make moral and other decisions. But in order for that to happen, according to Benson and Lindemann, those around us must afford us the power to act autonomously, and we have to have self-trust in our ability to do so.

Being forced to take on an identity that is disvalued or marginalized - a damaged identity, in Lindemann's terms - can result both in direct constraints on agency (if I as a disabled person am not able to attend school), and indirect effects, through the psychological harm to the individual that can follow from a lifetime of being treated as

\footnotetext{
${ }^{34}$ F. Baylis. Black as me: narrative identity. Developing World Bioethics 2003; 3: 142-50; 142 p 142)

${ }^{35}$ H. Lindemann Nelson. 2001. Damaged identities, narrative repair. Ithaca, NY: Cornell University Press.

${ }^{36}$ M. Schechtman. The constitution of selves. Ithaca, NY: Cornell University Press; 1996.

${ }^{37}$ P. Benson P. Free agency and self-worth. Journal of Philosophy 1994; 91: $650-668$.

${ }^{38}$ Ibid: 661
}

marginal or of less value (if I as a disabled person believe myself to be less knowledgable than others). And if certain identities are marginalized, disvalued or neglected, this will be reflected in the forms of identity narratives made available to them (see Lindemann Nelson ${ }^{39}$ for a fuller treatment). Thus, false or 'toxic' narratives that are used to assemble an identity will fundamentally damage agential capacity.

However, in addition to overtly negative narratives of disvalued identities, it is also possible for an identity narrative to be simply absent from the cultural repertoire, with similarly damaging effects on agency. A prime example would be when a new social position or role emerges so rapidly that the resources supporting an account of it are still rudimentary: the provision of a story that can be incorporated into a personal sense of self lags behind the appearance of the role itself. Past examples where this has happened are often to do with rapid and contested social change. In the recent history of the UK this could include the emergence of a black middle class, or of same-sex parents. It seems plausible that a person born through mitochondrial replacement will face similar difficulties, at least when MRT is first used. Her novel birth history, and the distinctive situations and problems she may confront, will not (yet) be present in the narratives of identity circulating within her community. She and her family may lack a vocabulary to match some crucial areas of her experience that arise out of the special way she was conceived, and a story that enables her to make sense of those aspects of her life and eventually to describe and account for them to others. ${ }^{40}$

It follows from this that an important question when evaluating the impact of MRT on identity is what kind of narratives of conception, birth, parentage and health status will emerge for the child born through MRT and his or her family (and donor) to use. The origin and identity stories told by parents and other kin to the child, the stories circulating within communities, and the wider cultural representations of 'kinds of people ${ }^{41}$ in a society, are mutually constitutive, and so inherently tending towards conservatism and at the same time open to change. Cultural representations circulate and are passed between generations through everyday speech, anecdotes, jokes, songs, family tales, written memoirs and other formal depictions. In contemporary society it is also clear that the 'stories that are made into other stories' are efficiently propagated through the mass information and entertainment industries, including online and print

${ }^{39}$ H. Lindemann Nelson, op.cit. note 35, p.16.

40 J.L. Scully. 2008. Disability Bioethics: moral bodies, moral difference. Lanham: Rowman \& Littlefield: 115-131.

${ }^{41}$ I. Hacking I. Kinds of people: moving targets. $10^{\text {th }}$ British Academy Lecture, 2006. Available at: http://nurs7009philosophyofinquiry.weebly. com/uploads/6/0/4/0/6040397/hacking_20071.pdf [Accessed 6 January 2016]. 
1 media, cinema and television, alongside the more traditional literary and dramatic forms. In what may turn out to be the early days of MRT, there are as yet no fictional 4 representations of mitochondrial disease or MRT in literature, cinema or television; the best we can do at the 6 moment is to extrapolate from the cultural representations of other modes of assisted conception.

Surveying the cultural representations of assisted conception and the related research literature, it is striking that apart from some publications on cultural representations mostly dating from the earlier days of assisted conception, there is little academic research in this area. ${ }^{42}$ Although there are now a number of novels, feature films or television dramas featuring some aspect of assisted conception, in practice they share features that suggest their role in the development of novel narratives of origin is restricted and potentially problematic. The existing narratives tend to take as their central theme a difficult and painful aspect of assisted conception, such as the emotional distress of infertility, or tensions between intended parents and a surrogate. In these representations, assisted conception is the problem that drives the drama. If we exclude technologies that are still science fiction (such as the routine genetic profiling and selection of the 1997 film Gattaca), one of the commonest themes is the anonymous gamete donor seeking or being sought by the resulting child. For example, the film The Kids are Alright (2010) charts the disruption in the lives of a lesbian couple and their two children when one child contacts his previously anonymous donor father. Leon the Pig Farmer (1992) is a comedy about a Jewish man who discovers that his biological father's job is exactly as stated in the title. These and similar examples are narratives of crises that arise solely from the manner of the child's conception. They are about a search for identity in the sense of finding a character's 'real' parent. In doing so, however, they dramatize rather than normalize the process of being conceived through donor insemination, and they fail to offer a useful strand of identity narrative for those donor children who do not want to know the identity of their donor. Films with this theme may even make donor conceived children assume that they should be experiencing an identity crisis and that there is something wrong with them if they don't. (This is potentially even more problematic: stories may primarily reflect how people's lives go, but the very availability of a handy story can also mean that these narratives become the obvious paths for a life to follow.)

\footnotetext{
${ }^{42}$ See for example S. Franklin S. Postmodern procreation: a cultural account of assisted reproduction. In Conceiving the new world order: the global politics of reproduction. F.D. Ginsburg and R. Rapp, eds, Berkeley and Los Angeles: University of California Press; 1995; 323-345; more recently J. Maher. Something else besides a father: reproductive medicine in recent Hollywood film. Feminist Media Studies 2014; 14: 853-867.
}

The paucity of fictional representations of assisted conception, the children born from them and the families they are born into, has several possible explanations. It could be that the technologies have already become part of the 'new normal' of family life: so effectively normalized that they are no longer felt to merit special (artistic or other) attention. However, this explanation becomes less plausible, I think, if we consider the lack of examples in which assisted conception is a purely incidental aspect of the plotline. The only coming near to this I could identify are in soap operas where, because characters tend to be presented for months or years, an initial plotline about the use of assisted conception can become peripheral as the story of that family is carried on (eg in the UK, the television programmes EastEnders, Coronation Street and Emmerdale Farm have all at different times included characters who consider using IVF). ${ }^{43}$ Beyond the distinctive narrative structures of soap opera, however, the lives of children born by assisted conception do not seem convincingly integrated into the normative narrative stock. ${ }^{44}$

Parallels can be drawn with the popular media representations of ethnic or sexual minorities, or disabled people. In these cases it has been argued that characters in film, theatre or television dramas are usually black, gay or disabled only if their ethnicity, sexual orientation or disability forms a central feature of the story. A character is deaf because the film is about deafness, not as one part of that character's profile. ${ }^{45}$ Similarly, for assisted conception normalization would mean that a drama could involve a child whose best friend was born through IVF, a fact mentioned in passing, in the same way that a character's employment or hobbies might be; their origins are an interesting but peripheral part of their character in a story about something else entirely.

Collective narratives may also draw from sources other than fiction, such as policy documents, public consultation materials and similar grey literature. Although not providing material that can straightforwardly be adopted as

\footnotetext{
${ }^{43}$ http://www.digitalspy.com/soaps/eastenders/spoilers/a308882/katand-alfie-make-a-decision/; http://www.thebabywebsite.com/article 3144.Whos_The_Legal_Mother_in_Coronation_Street_Surrogacy_ Story.htm; http://metro.co.uk/2014/03/22/emmerdale-ruby-and-aligo-to-desperate-lengths-to-achieve-their-baby-dream-4673258/.

${ }^{44}$ Complete normalization would also require openness within and beyond families about their use of ART. Although the HFEA and infertility support organizations encourage people to be honest with their children about their origins, the available evidence suggests that, although becoming more common, this does not always happen. I have also been told by three fertility specialists independently that their goal is for patients to be able to 'forget this [ie IVF] ever happened'.

${ }^{45}$ A. Enns \& C.R. Smit, eds. 2001. Screening disability: essays on cinema and disability. University of America Press; P.A. Darke. 2004. The changing face of representations of disability in the media. In Disabling barriers, enabling environments. J. Swain, S. French, C. Barnes, \& C. Thomas, eds. London: Sage: 100-105. 50 51 52 53 54 55 56 57 58 59 60 61 62 63 64 65 66 67 68 73 74 
narratives, these sources contribute language, imagery and empirical material so that policy can be revised and reshaped accordingly. In the case of MRT, official communications have been careful to frame it as a vital therapeutic procedure intended to support the birth of normal, healthy children within normally functioning families. The almost exclusive use of 'donation' and 'mitochondrial donor' (rather than 'transfer' or 'replacement') in these sources resonates with the generally positive attitude of the UK public towards tissue donation, and connects to existing social narratives about the virtue of organ and blood donors. Nevertheless, it is still unclear how immediately influential these sources are compared to popular media references. Likewise, the place of empirical studies in the development of cultural understandings of novel identities is, to my mind, still very uncertain. These forms of academic data clearly do contribute to the thinking that produces appropriate policy, on healthcare or child welfare for example, but since they are primarily directed at professional expertise it seems unlikely that empirical psychological or sociological studies play a major role in shaping public opinion, at least in the short term. This suggests that the focus of attention should be on more informal and popular representations than on academic data.

In the immediate future the most important influence on the development of master narratives of MRT will be factual news and social media. Here, it has to be acknowledged that the current discourse around MRT in these domains is pretty disappointing. Although media reporting of MRT always mentions its positive therapeutic goals, the other prominent themes are the technology's novelty and the '3-parent children' it will create, despite the deliberate efforts of governmental and regulatory bodies, and by scientists, clinicians and ethicists, to explain the inadequacies of that description. ${ }^{46}$ The language of the 3-parent child positions MRT children and their families as so unusual as to be morally suspect, and possibly even 'monstrous', and could conceivably lead to the emergence of severely damaging narratives of identity, particularly since the number of people using MRT is likely always to be much smaller than the numbers using more familiar forms of assisted conception.

\section{IMPLICATIONS}

Looking carefully at different models of how identity is formed and maintained indicates that mitochondrial transfer could indeed have a significant effect on the

\footnotetext{
${ }^{46}$ Numerous examples are available, for example: 'Three parent babies explained: what are the concerns and are they justified?' The Guardian, 2 February 2015; 'UK becomes first country in the world to legalise threeparent babies after Lords approves controversial IVF technique', Mail Online 24 February 2015; 'Three parent babies could risk the future of the human race, warn 55 Italian MPs', Express 21 February 2015.
}

identity of the child (and his or her family) born through MRT, but not through the routes that have so far received most bioethical attention. Mitochondrial transfer will certainly modify an embryo's total genetic composition, but this purely genetic change has little to do with what we normally think of as a person's identity. There is no scientific evidence at present that a switch of mtDNA will alter other identity-forming features, although that may change in the course of future research, nor do we know whether or in which cases any change would be significant, and whether it would be harmful or beneficial. However, we can say that if MRT works as hoped, it will change the identity of the resulting child in a profound and highly beneficial way by protecting it from mitochondrial disease. Meanwhile, although as yet there is no possibility of evidence about MRT's effect on identity through family relationships, longer experience with other forms of assisted conception has given no indication of obviously harmful outcomes specific to their use. It is impossible to know at this stage if the same will apply to children born from MRT. However, since at least the first cohort of these children will have long term health follow-up, it would make sense to include in this an effort to detect any difficulties with identity that do emerge, and where possible indicate ways of compensating.

I have argued that it is the social processes that form and maintain identity, through the narratives that the family and wider community adopt, that present the most likely route for MRT to have a significant effect on the child's sense of self. Families who have undergone MRT in order to have a healthy child are likely to favour the most positive accounts. In the wider community, however, attitudes to new biomedical technology are unpredictable and are strongly influenced (positively or negatively) by media reporting, especially of particularly newsworthy cases that may not be representative of the technology as a whole. What matters is whether a society treats children born through MRT as worryingly anomalous bearers of an 'artificially constructed identity', ${ }^{47}$ or whether the story that comes through is of being just part of the 'new normal' of family life, which to a certain extent has happened for families generated through more familiar forms of genetic and reproductive technology. Concerns that society would view children born from MRT with suspicion, as well as the converse belief that MRT will eventually be accepted 'as new advances always are, ${ }^{48}$ were also expressed by a few respondents to the HFEA open consultation, although given in the

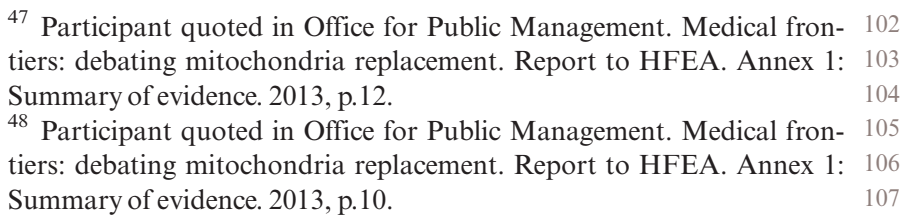
47 48 49 50 51 52 53 54 55 56 57 58 59 60 61 62 63 64 65 66 67 68 69 70 71 72 73 74 75 76 77 78 79 80 81 82 83 84 85 86 87 88 89 90 91 92 93 94 95 
context of discrimination rather than identity. It is possible that the present media emphasis on MRT as producing healthy but unnatural embryos, children and families will persist, and may culminate in resistance to the technology and, crucially, a failure to elaborate positive narratives of identity that are familiar to and accepted by the general public.

If identity is created in part through cultural narratives, and can be damaged in a morally significant way by the lack of a 'good story', then ensuring that such good stories are available to MRT children and their families becomes a collective moral responsibility. This conclusion carries implications for what the state, public health policymakers, healthcare providers, regulators, patient groups and society as a whole might need to do in order for MRT to be introduced in an ethically responsible way. For example, it may become necessary to establish a form of systematic monitoring to follow how the media and other social institutions discuss MRT children and families, and engage with these agencies to counter potentially hurtful, harmful or limiting identity stories with more nuanced ones based on accurate empirical knowledge. A consciousness of what stories can do for and to people leads to the question of whether narratives of identity can be manipulated strategically to create a more accurate repertoire for people born via MRT to choose from, in the way that disability 27 activism led over time to the creation of new narratives 28 of disability. Which methods are needed to satisfy 29 this collective responsibility in practice, whose task it 30 would be and how it would be resourced, are questions 31 that call for more extensive exploration involving all 32 stakeholders.

There are also wider implications for bioethics as a whole. The question of identity arose early in the discussion of MRT because it involves an actual, heritable genetic change, but if our thinking about the bioethical significance of identity expands to include the ways in which it can be shaped by culturally validated narratives as well as through a person's experience of illness and disability or family dynamics, then it becomes clear that a variety of other medical and biotechnological contexts also, unexpectedly, raise issues of personal and social selfhood and self-determination. An ethically responsible approach to innovative research requires noticing not just how scientific ideas and interventions change people's lives in the most obvious ways, but also how they change who people think they are (or should be), and the stories that they tell about themselves.

Jackie Leach Scully is Professor of Social Ethics and Bioethics, and Co-Director of the Policy, Ethics and Life Sciences Research Centre, Newcastle University.

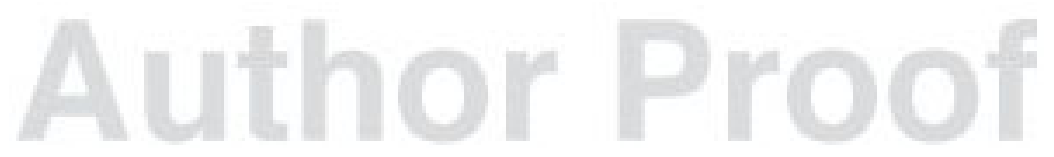




\section{AUTHOR QUERY FORM}

Dear Author,

During the preparation of your manuscript for publication, the questions listed below have arisen. Please attend to these matters and return this form with your proof.

Many thanks for your assistance.

\begin{tabular}{|l|l|l|}
\hline $\begin{array}{l}\text { Query } \\
\text { References }\end{array}$ & Query & Remarks \\
\hline AQ1 & Please confirm that given names (red) and surnames/family names (green) have been identified correctly. & \\
\hline
\end{tabular}

